\title{
Antecedents of Knowledge Gaps: Parenting Knowledge and Early Childhood Cognitive Development-Review and Call for Research
}

\author{
Cecilie Gaziano*
}

Research Solutions, Inc., 4511 Fremont Avenue South, Minneapolis, MN 55419-4744, USA

\begin{abstract}
Communication researchers have long been concerned about knowledge gaps, but few realize that knowledge gaps are rooted in early childhood learning differentials to which socioeconomic disparities contribute. The purpose of this paper is to illuminate understanding of the processes that contribute to knowledge gaps during the earliest stages of life and to invite communication researchers to study early childhood interventions, which can be considered communication interventions. Communication researchers seldom may be directly concerned with early developmental processes, but they may wish to become more involved in such interventions. Ultimately, communication outcomes for adults can be enhanced. Early interventions aimed at primary caregivers at risk of poor parenting can improve parenting knowledge and proficiency, thereby contributing to enhanced cognitive development of their children. The prenatal and early postnatal periods are times when parents are both vulnerable and open to support and new information. Three examples of knowledge measurement instruments and three examples of interventions to facilitate parental sensitivity to their infants' cues and to enhance parents' knowledge of child development are described. Researchers are encouraged to conceptualize future research with prospective, longitudinal designs, which could begin even before babies are born and follow children from birth through adolescence or adulthood, drawing concepts also from socialization theories. Communication researchers seldom may think about children in the context of the knowledge gap, but perhaps the time has come for them to use their talents and work with child development professionals and those in related areas to reduce parenting knowledge and skills gaps.
\end{abstract}

Keywords: Knowledge gap, cognitive development, attachment theory, family communication patterns, parenting interventions, early childhood, Matthew effect.

\section{INTRODUCTION}

Understanding how people become informed and active citizens is a crucial goal of social science (Delli Carpini \& Keeter, 1996). Many studies link differentials in knowledge and civic participation to differentials in socioeconomic status (Gaziano, 1997; Gaziano \& Gaziano, 2009; Hwang \& Jeong, 2009; Tichenor, Donohue, \& Olien, 1970; Viswanath \& Finnegan, 1996). Most of these studies support the knowledge gap hypothesis that posits that increases in information circulating within a social system tend to widen knowledge differentials between high and low status groups rather than lessen them over time (Tichenor, Donohue, \& Olien, 1970). Better understanding of these processes can help to decrease some of the impediments to democratic participation. The purpose of this paper is to discuss the processes that contribute to knowledge gaps occurring during the earliest stages of life by focusing on differentials in parents' childrearing knowledge as a major component of knowledge gaps and to invite communication researchers to consider conducting more work in this area.

A large body of evidence now exists concerning conditions that promote healthy developmental processes for children. Although important research has been carried out on early childhood education in school settings, this paper will

*Address correspondence to this author at Research Solutions, Inc., 4511 Fremont Avenue South, Minneapolis, MN 55419-4744, USA;

Tel: +1 (612) 825-8887; Fax: +1 (612) 825-1966;

E-mails: cgaziano@prodigy.net, cgaziano1@gmail.com focus on research on parents of infants and young children in the first years of life as the most critical time for cognitive development.

A theoretical framework that accounted for differences in the distribution of families' childrearing patterns as an important factor in the development of knowledge gaps in adulthood is useful here (Gaziano, 2001). The framework highlighted four childrearing prototypes by using Baumrind's three primary parenting types (1966, 1968, 1971, 1994, 1996), combined with concepts from Maccoby and Martin (1983), as well as attachment theory, authoritarian personality theory, and Kohn's theory of childrearing values (1976, 1977). It demonstrated how the concept of power underlay these components on the levels of the individual, the family, and society. These factors influence the ways in which parent-child interactions imbue children with a sense of efficacy or powerlessness, which ultimately shapes their perceptions of self-efficacy and power relations in parenting and in citizenship as adults.

Baumrind's concepts of parental demandingness and responsiveness to children's emotional needs were cross tabulated to form a four-celled table (Baumrind, 1966, 1968, 1971, 1994, 1996; Maccoby \& Martin, 1983). Demandingness includes means by which parents assert control, discipline, and punishment. Responsiveness is an affective component, parent-child warmth. The four resulting prototypes are authoritative, permissive, authoritarian, and unengaged. In actuality, parenting styles may show evidence of mixtures of these types (Baumrind, 1971, 1994, 1996). To a certain 


\begin{tabular}{|c|c|c|}
\hline \multicolumn{2}{|c|}{ Demandingness } \\
\hline Responsiveness to Children's Emotional Needs, Nurturance & High & Low \\
\hline \hline High & $\begin{array}{c}\text { Authoritative High knowledge of } \\
\text { child development }\end{array}$ & $\begin{array}{c}\text { Permissive/Indulgent Moderate knowledge of } \\
\text { child development }\end{array}$ \\
\hline Low & $\begin{array}{c}\text { Authoritarian Moderate to low } \\
\text { knowledge of child development }\end{array}$ & $\begin{array}{c}\text { Unengaged/Neglectful Lowest knowledge of } \\
\text { child development }\end{array}$ \\
\hline
\end{tabular}

Fig. (1). Combined model of Baumrind's and Maccoby and Martin's parenting styles.

extent these prototypes correspond to the four-fold family communication typology, respectively, of consensuals, pluralistics, protectives, and laissez-faire families (e.g., McLeod \& O'Keefe, 1972; Ritchie, 1991; Tims \& Masland, 1985 [1]. The theoretical framework posited that family childrearing patterns influence the development of abstract thinking, motivation, and knowledge (Gaziano, 2001). Fig. (1) depicts this framework.

Authoritative parents tend to allow reasoned discussion, including conflict and disagreement, to provide explanations, and to rely more on persuasion than punitiveness to assert control. Their children tend to be highly motivated and achievement oriented.

Permissive parents prefer to avoid conflict and control, although they may be angry because they do not have control (Baumrind, 1994, 1996). Their use of control can employ reason, manipulation, or indulgence. Their parent-child communication often emphasizes give and take, as well as reasons for rules. Their children may be less responsible than those parents would desire, and the children may also be less curious and self-disciplined than children of authoritative parents.

Authoritarian parents are parent-centered, oriented to assigned roles and power differentials (Baumrind, 1968, 1994). They tend to be high in demandingness but also tend to assert control in arbitrary, inconsistent, and even harsh or abusive ways. They tend to be less in tune with their children's emotional needs. Obedience is valued over self-reliance, and respect for authority is preferred to independence and autonomy. Their children are more likely to be low achievers or rebellious.

Unengaged parents are the most likely to neglect or be indifferent to their children, intentionally or unintentionally (Baumrind, 1994; Maccoby \& Martin, 1983). Among the four types, they are the most likely to be poorly educated, impoverished, and lacking in childrearing knowledge (Crittenden, 1985; 1996). Support networks, if they have them, are also likely to be poorly informed about childcare.

The framework highlighted a number of propositions and hypotheses (Gaziano, 2001). The present paper will concentrate on evidence for those that are concerned with influences on knowledge, which are renumbered and slightly reworded here.

Proposition 1: Family childrearing patterns influence the development of knowledge in the child.

Proposition 2: The distribution of family childrearing patterns, or family prototypes, is unequal in society.
Hypothesis 1: Families with authoritative childrearing patterns will be found most often in upper levels of social strata, followed by permissive families. Authoritarian families will be at lower levels. Families characterized by unengaged childrearing patterns will be at the lowest levels.

Hypothesis 2: Members of authoritative families will exhibit the highest levels of knowledge, followed, in order, by permissive families, authoritarian families, and unengaged families.

\section{SUPPORT FOR THE PROPOSITIONS AND HY- POTHESES}

Many studies find low levels of parents' knowledge about child development among less advantaged groups. It therefore seems more important to concentrate on interventions to give those parents tools to build their understanding and warmth of communication. The research supporting the propositions and hypotheses will be discussed below, followed by a call for increased efforts to develop research interventions, especially by communication researchers.

Some researchers of children's development and abilities find results they call the "Matthew effect"; that is, those who have will obtain more, and the disadvantaged cannot catch up (e.g., Bakermans-Kranenburg, van IJzendoorn, \& Bradley, 2005; Merton, 1968). This term is based on the Gospel of Matthew 25:29 in the King James Version of the Bible [2]. This phenomenon is similar to what many communication researchers call the knowledge gap, as hypothesized by Tichenor, Donohue, and Olien (1970, pp. 159-160):

"As the infusion of mass media information into a social system increases, segments of the population with higher socioeconomic status [SES] tend to acquire this information at a faster rate than the lower status segments, so that the gap in knowledge between these segments tends to increase rather than decrease."

SES predicts neurocognitive performance, especially for language and executive functions, and SES differences are evident as early as infancy (Hackman \& Farah, 2009). Poverty and environment tend to account for IQ differences in lowest SES children, while genes account for IQ differences in higher SES children (Turkheimer, Haley, Waldron, D'Onofrio, \& Gottesman, 2003). SES differences in child brain functioning occur before formal schooling experiences, according to many studies (Hackman \& Farah, 2009). Primary causes of these differentials include the effects of SES on prenatal influences (increased likelihood of premature birth, impaired fetal growth, higher levels of stress infection rates, poor nutrition), parental care (stress, conflict, problematic behavior), and quality of and available cognitive stimu- 
lation in the home environment (Hackman, Farah, \& Meaney, 2010; Turkheimer, Haley, Waldron, D’Onofrio, \& Gottesman, 2003). Nurturing and well-ordered aspects of children's home environment, cognitive stimulation, and maternal sensitivity can be important moderating influences on neurocognitive functioning of lower SES children, however (Farah, Betancourt, Shera, Savage, Giannetta, Brodsky, Malmud, \& Hurt, 2008; Hackman, Farah, \& Meaney, 2010; Petrill \& Deater-Deckard, 2004; Petrill, Pike, Price, \& Plomin, 2004).

By age 3, children of middle class families and children of lower class families have a vast gap in vocabulary development (Hart \& Risley, 1995, 2003). Children's proficiency at age 3 predicts later language skills in elementary school, according to Hart and Risley (1995, 2003), who gathered data from 42 families for two and a half years and followed the children to ages 9 or 10 . They found a striking difference between middle class and lower class families not only in amount of feedback and vocabulary development, but also a difference in the amount of encouraging feedback given to young children. The gap was even wider when children of welfare parents were compared with lower class and middle class children. Further, the lower the class, the greater the amount of parental discouragements to children.

The largest influence on differentials in children's development, their ability to learn, and their environment (family, neighborhood, schools, and other institutions) is poverty. The lower the SES, the greater the effects on cognitive skills (Hackman \& Farah, 2009). Poverty restricts families' ability to devote emotional resources to their children and to find or use resources that would aid their children's development, and it hinders the ability of many parents to provide an environment in which learning can take place (Brooks-Gunn, Klebanov, \& Duncan, 1996; Neuman, 2006a, 2006b; Totsika $\&$ Sylva, 2004). Poor nutrition, health, and housing multiply these problems (Neuman, 2006a, 2006b). These conditions appear to be far more destructive during the early years when cognitive connections are forming than during later adolescent years (Duncan and Brooks-Gunn, 1997; Hackman \& Farah, 2009; Neuman, 2006a).

Deficiencies in parenting skills and parents' knowledge about child development are often related to child maltreatment (Berger \& Brooks-Gunn, 2005; Cowen, 2001; Izzo, Eckenrode, Smith, Henderson, Cole, Kitzman, \& Olds, 2005). Child maltreatment decreases cognitive development, perceived self-efficacy, and self-esteem. Risk factors for maltreatment include lower SES, minority race or ethnicity, giving birth in adolescent years, preterm infants, single marital status, history of abuse as a child, and lack of social support networks (Bavolek, 2001b; Lutenbacher \& Hall, 1998; Olds, Eckenrode, Henderson, Kitzman, Powers, Cole, Sidora, Morris, Pettitt, \& Luckey, 1997; Pfost, Stevens, \& Lum, 1990).

The multiple stresses of poverty are an underlying factor. Stresses influence parental affect, and negative parental affect (anger, irritability, sadness, depression, hostility, fear) tends to be related to harsh parenting behaviors, according to the meta-analysis of Rueger, Katz, Risser, and Lovejoy, 2011). Stress even affects child IQ (Brown \& Rosenbaum, 1984). Among more than 4,000 7-year-olds, children who were experiencing emotional or physical stress had an average of $13 \%$ lower scores on intelligence tests, compared with children who were not stressed (Brown \& Rosenbaum, 1984). Stresses included high mobility, deaths in the family, divorce, parents' employment or unemployment, low income, large families, and short intervals between births, among other conditions.

Much of the research concerns parents at risk of abuse and neglect. It frequently focuses on facilitation of infant attachment to the primary caregiver because attachment plays a vital role in the development of cognitive abilities and motivation to learn (de Ruiter \& van IJzendoorn, 1993). One of the most powerful variables that account for acquisition of knowledge is interest (Gaziano, 1997; Viswanath \& Finnegan, 1996), so improving motivation to learn at an early age has important implications for development of informed, interested citizens.

When primary caregivers who are at risk for poor parenting and child maltreatment, usually mothers and often of lower SES, have access to information and training to facilitate good parenting, especially that which builds on their strengths, they frequently are able to improve parenting skills and provide more nurturing and intellectually stimulating environments for their children. Most studies seeking to improve parenting knowledge demonstrate at least a small effect, even for short-term assessments. Increasing parenting knowledge helps to reduce stress and parent-child dysfunctional interaction (Belcher, Watkins, Johnson, \& Ialongo, 2007) and to reduce the relation between SES and knowledge (Rowe, 2008). In addition, knowledge of child development was associated with improved home safety and was especially important for caregivers with poor mental health in a study of mothers living in poor, rural communities (Zolotor, Burchinal, Skinner, Rosenthal, \& Key Life Investigators, 2008).

These results indicate that levels of parenting knowledge are at lower levels among parents who fit the descriptions of authoritarian and unengaged. The results support the proposition that the knowledge gap is rooted in a parenting knowledge gap, not because parents with lower SES are predisposed to be poor parents but because many factors linked to lower SES inhibit their ability to parent their children as well as they would wish (Bavolek, 2001b; Lutenbacher \& Hall, 1998; McLoyd, 1990; Olds, Eckenrode, Henderson, Kitzman, Powers, Cole, Sidora, Morris, Pettitt, \& Luckey, 1997; Pfost, Stevens, \& Lum, 1990). Being of higher SES does not ensure that parents will be more knowledgeable; however, possessing higher SES provides more access to resources that support good parenting. Further, the greater the lack of parenting knowledge, the greater the chances that parents will operationalize power through harsh, punitive methods out of their sense of low self-efficacy. Attitudes of authoritarianism, intolerance, distrust, and low self-efficacy are related to lower levels of education, cognitive ability, motivation, and knowledge (McLeod \& Perse, 1994; Oliver \& Armstrong, 1995; Peterson, Duncan, \& Pang, 2002; Simmons \& Garda, 1982).

Although permissive parents may need more information about these areas, they seem to have been studied less than authoritarian and unengaged parents. Perhaps this is because 
they tend to be of higher SES and may have access to more resources than authoritarian and unengaged parents. Authoritative parents exemplify an ideal, but in reality, they may lack enough parenting knowledge initially but usually have resources to acquire it. The research usually involves interventions to increase parenting knowledge and sensitivity. Most take place in home visiting situations [3].

\section{ASSESSMENTS OF PARENTING KNOWLEDGE}

Three frequently used instruments are described here as representative of the various methods that measure parenting knowledge: the Infant-Toddler Home Observation for Measurement of the Environment (IT-HOME), the Adult Adolescent Parenting Inventory (AAPI), and the Knowledge of Infant Development Inventory (KIDI). They cover such elements as children's emotional, social, cognitive, and health needs, and safety of their environments. (See the Appendix for information on obtaining these instruments).

\section{Infant-Toddler HOME Inventory}

The IT-HOME Inventory for ages 0-3 is designed to capture aspects of the child's home atmosphere that nurture and stimulate emotional, cognitive, and behavioral development (Bradley \& Caldwell, 1988; Caldwell \& Bradley, 2001). A trained assessor, often a visiting nurse or a paraprofessional, conducts a semi-structured interview with the primary caregiver, usually the mother, and also observes the physical environment during a period of about an hour. Higher scores indicate a larger number of positive elements in the home environment. Scores in the lowest one-quarter of the range denote a setting that contains risk to healthy child development. Reliability coefficients for the subscales have ranged from .44 to .88 or higher.

The IT-HOME covers six dimensions (see, e.g.: Bradley \& Caldwell, 1988, p. 98; Linver, Brooks-Gunn, \& Cabrera, 2004, pp. 101-102). It includes such components as "Emotional and verbal responsivity of mother" (praising the child, showing affection, and reacting positively to the child's vocal expressions), "Organization of physical and temporal environment" (child's play environment is safe) and "Provision of appropriate play materials" (toys and other items available for physical development, eye-hand coordination, and cognitive development). Examples of subscale items for "Avoidance of restriction and punishment" are: "Parent does not shout at child during visit" and "Parent does not express annoyance with or hostility to child." Other subscales are "Maternal involvement with child" (keeping child in visual range, talking to child while doing household work) and "Opportunities for variety in daily stimulation" (child eats at least one meal a day with parent/s, child has three or more books of his/her own).

Research over several decades finds a strong correlation between the IT-HOME Inventory and cognitive competence (Totsika \& Sylva, 2004). The IT-HOME reflects the qualities of caregiver sensitivity and responsiveness to the child, which contribute indirectly to cognitive development by strengthening attachment of the child to the caregiver (attachment is discussed more fully below). Although SES and maternal IQ are correlated with IT-HOME scores, the ITHOME can predict cognitive proficiency independently of these two variables.
It is more sensitive to caring aspects of white family settings, however, although it describes positive features of non-white environments (Totsika \& Sylva, 2004). Whether or not a family lives in poverty is a more crucial variable for development than is race or ethnicity. IT-HOME scores of poor children tend to be significantly different from scores of non-poor children because poverty diminishes the physical environment, intellectual stimulation, and parental warmth (Totsika \& Sylva, 2004). However, some differences between poor and non-poor mothers occur in part because of cultural attitudes, such as a tendency of European American parents to perceive their children as capable of learning at an earlier age than did Latino and African-American mothers (Bradley, Corwyn, McAdoo, \& Garcia Coll, 2001).

Kendrick and her colleagues (2000) obtained 34 reports of randomized controlled trials and quasi-experimental studies with control groups involving home visiting interventions that included at least one postnatal visit. Of these, 17 utilized HOME scores, 27 used other measures, and 10 combined HOME and other instruments. Overall, home visiting was significantly effective. Their criterion was quality scores with the Reisch scale, which ranges from 0 to 1 , with higher scores indicating higher quality reports. Another review of 48 published articles and 56 intervention effects $(\mathrm{N}=7,350)$ found a combined effect size of Cohen's (1988) $d=.20$ [4], interpreted as small, for total IT-HOME scores $(\mathrm{p} \leq .001)$ (Bakermans-Kranenburg, van IJzendoorn, \& Bradley, 2005).

Such interventions were more successful with bettereducated, higher income, non-adolescent participants. Better results were found for more short-term interventions, a moderate number of sessions, and participants' home settings, as opposed to other settings such as healthcare clinics (Bakermans-Kranenburg, van IJzendoorn, \& Bradley, 2005). Nevertheless, others have shown that less advantaged or adolescent parents can benefit from such interventions because after receiving interventions they are more likely be involved in their children's school activities and less likely to maltreat their children (Reynolds \& Robertson, 2003).

Advantages of the IT-HOME Inventory are ease of training assessors, use, interpretation, and its non-threatening character. Disadvantages include lack of standardized means of administration, its yes-no scoring that misses nuanced information, and its inability to discriminate between one instance of a behavior and multiple instances of it (for example, number of times the child was punished during the last week) (Totsika \& Sylva, 2004). The IT-HOME scale consists of both observed and self-reported items, and the mother is usually the reporter. Drawbacks are potential bias of social desirability and only one informant fills it out on only one occasion (Totsika \& Sylva, 2004). Risk factors such as maternal learning disabilities, medically fragile children, maternal psychopathology, parental substance abuse, and preterm infants need more in-depth measurement (Totsika \& Sylva, 2004). Previous research has shown that the more risk factors that are present, the more complicated intervention programs must be (Greenspan \& Wieder, 2006; Kowalenko, Barnett, Fowler, \& Matthey, 2000). The ITHOME Inventory has been used widely, refined, and found to be reliable and valid since its development in the 1960 s 
but should be supplemented by other measures of parenting quality (Totsika \& Sylva, 2004).

\section{Adult Adolescent Parenting Inventory}

The AAPI is a self-administered instrument that measures knowledge of and attitudes toward parenting. Low scores correlate with higher potential for child abuse. The first version of it identified four parenting and child-rearing constructs most commonly associated with abusive parents. It had two forms, A and B, each with 32 items written on a sixth grade reading level that formed four subscales: appropriateness of expectations of children, presence of empathetic awareness of children's needs, strength of belief in the use of corporal punishment, and appropriateness of perceived parent-child roles (Bavolek, 2001a). It has been updated as the AAPI-2, also in forms A and B, each with 40 items, including a fifth subscale concerning supporting or oppressing children's power and independence. Participants are instructed to reply whether they strongly agree, agree, strongly disagree, disagree, or are uncertain about each item. No time limit is set for completion; usually, the test takes 20 to 30 minutes. Raw scores are standardized and used to compute "sten" scores (standardized ten-scale scores) and "normed" - so that a given individual can be compared with the normal distribution of scores of certain subpopulations into which participants fall, such as males and females, blacks, whites, adolescents, and adults. The risk for child abuse is determined when the score is compared with abusive or non-abusive subgroups. Examples of items are:

- "Young children should be expected to comfort their mother when she is feeling blue."

- "Parents should never use physical punishment to teach their children right from wrong."

Overall scale reliabilities have ranged from Cronbach's alpha of .69 to .86 or more (Gorzka, 1999; Lutenbacher \& Hall, 1998). Higher scores on the AAPI, as on the ITHOME, tend to be correlated with possessing higher education and income, living in less crowded homes, and being older, Caucasian, employed, multiparous, or married (Bavolek, 2001b; Pfost, Stevens, \& Lum, 1990; East, Matthews, \& Felice, 1994).

Among surveys using it with a home visiting component, five reported small to medium sized effects (Barnet, Duggan, DeVoe, \& Burrell, 2002; Barnet, Liu, DeVoe, AlperovitzBichell, \& Duggan, 2007; Cowen, 2001; Culp, Culp, Blankemeyer, \& Passmark, 1998; Guthrie, Gaziano, \& Gaziano, 2009), and two found no significant effects (Barlow, Davis, McIntosh, Jarrett, Mockford, \& Stewart-Brown, 2007; St. Pierre \& Layzer, 1999). These investigations varied in type of visitor, design, sample size, and sample characteristics, although all concerned parents at risk, primarily women and girls. Four studies of other populations noted at least small effects on the AAPI or one of its subscales (Gorzka, 1999; Lutenbacher \& Hall, 1998; Sasso \& Williams, 2002; Woods, Obeidallah-Davis, Sherry, Ettinger, Simms, Dixon, Missal, \& Cox, 2003), and two observed large effects on this measure (Hurlbut, Culp, Jambunathan, \& Butler, 1997; Thomas \& Looney, 2004). Some have cautioned that the total score may be more useful than some of the subscales (Conners, Whiteside-Mansell, Deere, Ledet, \&
Edwards, 2006). The AAPI-2 is a self-report and, as such, can be biased (Linver, Brooks-Gunn, \& Cabrera, 2004). Combining it with structured interviews, and/or videotaped sessions with mothers and infants, and other relevant measures can provide more objective data.

\section{Knowledge of Infant Development Inventory}

One of the better-known measures of parenting knowledge is the KIDI, developed by MacPhee (1981) as a parent report aimed at a seventh grade reading level that can be completed in about 20 minutes. The KIDI contains 75 items that are scored as right $(+1)$, wrong $(-1)$, or not sure (0). Some studies use fewer items selected from these. Subscales can be obtained for (a) norms and milestones, (b) principles, (c) parenting, and (d) health and safety. Its companions are a 25-item questionnaire measuring previous experience with infants (Catalogue of Previous Experience with Infants, or COPE) and a manual. Examples of questions from the KIDI include: [Agree, disagree, or not sure]

- "The baby should not be held when he (she) is fed because this will make the baby want to be held all of the time."

- "Talking to the baby about things he (she) is doing helps the baby's development and later competence."

Among studies reporting effect sizes or enough information to calculate them were Benasich \& Brooks-Gunn (1996) and Wagner, Spiker, \& Linn (2002). Benasich \& BrooksGunn (1996) described a prospective, longitudinal, randomized clinical trial of a low birth weight, preterm infant cohort. It included two treatment groups, an intervention group receiving comprehensive education and high-quality pediatric care through age 3 and a follow-up only group receiving the pediatric care. Although child characteristics were not associated with mothers' knowledge, maternal characteristics were. Caucasian mothers had significantly more accurate knowledge scores than African-American mothers at 12 months and 24 months; however, African-American mothers were less educated, younger, and less likely to be married, compared to Caucasian mothers. Heath status was highly related to cognitive outcomes for African-American youngsters.

Wagner, Spiker, and Linn (2002) evaluated a Parents As Teachers (PAT) program, enrolling low-income families at three sites when children were less than 8 months of age and randomly assigning them to the PAT group (involving home visits once a month or more often until children were 3 years of age) or a comparison group. When the participants were divided into very low income and more moderate income groups, a significant moderate effect size of $d=.33$ was found for the very low income treatment group, compared with the very low income comparison group. No effect occurred for the more moderate income group.

The KIDI is a self-report, subject to the biases of selfreports; however, the KIDI in both long and short forms is widely used and has been shown to be consistently valid and reliable since development in the early 1980s. As with the IT-HOME and AAPI, supplementing it with structured interviews, videotaped interactions of mothers and/or other measures of parenting quality is desirable. Hamilton and 
Orme (1990) demonstrated construct validity for the KIDI, as well as two other measures of parenting knowledge, and the KIDI was equally valid for poor black and poor white mothers in their sample. Its internal consistency reliability in a sample of mothers in Chapel Hill, North Carolina, was .82 (Cronbach's alpha) and .85 (Guttmann split-half coefficients) (MacPhee, 1981). Coefficients were somewhat lower in samples of college students and professionals. Parents in a study of developmentally delayed children scored significantly lower than parents of children with normal development in the number of items attempted and the number answered accurately. Test-retest reliability correlation coefficients for parents (2-week interval) were .92, total score; .80, attempted; and .91, accuracy.

\section{Other Measures of Potential Interest}

Including measures of parenting stress would be beneficial. For example, Munz, Wilson, \& D'Enbeau (2010) used the distress subscale of the Child Abuse Potential Inventory (CAPI) with the IT-HOME, finding that a sample of lowincome mothers may need extra help to cope with stress and relationship problems and, in fact, may view most or all relationships as fraught with problems. Other examples are the Parenting Stress Index (PSI) (see: Belcher, Watkins, Johnson, \& Ialongo, 2007), the General Health Questionnaire measure of maternal emotional distress (see: Berger \& Brooks-Gunn, 2005), the Brief Symptom Inventory (see: Zolotor, Burchinal, Skinner, Rosenthal, \& Key Life Investigators, 2008), and the Kempe Family Stress Check List (Korfmacher, 2000).

Another instrument of potential interest is the Working Model of Child Interview (WMCI), which has subscales that capture maternal representations of the infant and of the self as a mother/parent: richness or poverty of the mother's picture of the infant, flexibility or rigidity to accept new information about the infant, coherence of the mother's narrative about the infant, ability of the mother to perceive and respond satisfactorily to the infant's needs and experiences, and ability to accept the responsibilities of adequate caregiving (Huth-Bocks, Levendosky, Bogat, \& von Eye, 2004; Zeanah, Benoit, Hirshberg, Barton, \& Regan, 1994).

\section{INTERVENTIONS TO ENHANCE SENSITIVITY}

\section{Infant Attachment to the Primary Caregiver}

Attachment theory is highly relevant to cognitive and motivational development in young children (de Ruiter \& van IJzendoorn, 1993; Sroufe, 1983). Attachment theory and knowledge gap theory intersect through concepts of trust and self-efficacy, which foster thinking, problem solving, information processing, and attitudes toward learning (Gaziano \& Erickson, 2000). Attachment theory proposes that the infantcaregiver relationship provides the foundation for the development of trust, connectedness, and confidence to explore and learn. Human infants are powerfully predisposed to form attachments with parents or other adults who care for them, but the quality of those attachments varies with the type of care the adults provide (Ainsworth, Blehar, Waters, \& Wall, 1978; Erickson, as reported in Gaziano \& Erickson, 2000, p. 7). As longitudinal studies document, differences in the quality of attachment in the first year of life predict differences in attitudes and behavior in subsequent stages of development from preschool to adulthood (Erickson, Sroufe \& Egeland, 1985; Egeland \& Erickson, 1999; Erickson, in Gaziano \& Erickson, 2000; Grossman, Grossman, \& Waters, 2005; Sroufe, 2005).

Attachment theorists trace its roots to the 1960s and earlier ideas of Freud, and they describe how a mother's or other main caregiver's ability to perceive a child's needs and responsiveness to the child's behavior and signals are major determinants of secure attachments when children are about 12 months to 3 years of age (Ainsworth, Blehar, Waters, \& Wall, 1978; de Ruiter \& van IJzendoorn, 1993).

Attachment is classified generally as either secure or anxious. Securely attached infants trust that their caregivers will comfort them in times of distress because their own cues and signals have been responded to (Erickson, as reported in Gaziano \& Erickson). They develop confidence in their ability to seek the care they need and use their major attachment figures as a secure base from which they can explore their environment (Ainsworth, Blehar, Waters, \& Wall, 1978; Bowlby, 1988). This is a first, important experience of competence or self-efficacy. At later stages of development and across a variety of settings, children with a history of secure attachment are more confident and competent (Ainsworth, Blehar, Waters, \& Wall, 1978; de Ruiter \& van IJzendoorn, 1993). A history of insensitive, inconsistent, or unresponsive care results in an anxious attachment relationship. Anxious attachments can be subdivided further into three types, all of which reflect distrust and powerlessness on the part of the child (Erickson, in Gaziano \& Erickson, 2000, p. 8). They are characterized as anxious-resistant, anxious-avoidant, and disorganized/disoriented (Ainsworth, Blehar, Waters, \& Wall, 1978; Main \& Solomon, 1986).

Type of attachment is related to presence and quality of interpersonal support systems, community connectedness, and ability to maintain other types of relationships. By the time children start school, security of attachment has already formed their openness to new experiences and information, and many children have learned defenses against new behaviors and knowledge (de Ruiter \& van IJzendoorn, 1993; Sroufe, 1983). Correlated with SES, this phenomenon helps to set the stage for knowledge and behavior gaps in adulthood.

Childrearing styles among families experiencing severe stresses, especially stresses created by poverty, influence security of attachments (Ainsworth, Blehar, Waters, \& Wall, 1978; Erickson, Korfmacher, \& Egeland, 1992; Sroufe, 1983). Greater security of attachment is a protective factor for high-risk children (de Ruiter \& van IJzendoorn, 1993). A prospective study supported the hypothesis that maternal mental representations of the baby and related variables contributed to attachment security rather than vice-versa and also showed that risk factors such as poverty, low SES, single parenthood, and domestic violence were highly related to less secure mental representations of the infant (Huth-Bocks, Levendosky, Bogat, \& von Eye, 2004). Success has been reported in work with parents vulnerable to the multiple stressors of low SES to increase their abilities to form stronger attachments with their children (de Ruiter \& van IJzendoorn, 1993; Erickson, Korfmacher, \& Egeland, 1992; 
Sroufe, 2005). More emphasis on supporting vulnerable families at this life stage could increase these children's willingness to learn new knowledge and undergo new experiences.

A meta-analysis of 70 reports of sensitivity and attachment interventions in early childhood included 88 intervention effects on parental sensitivity to infants' emotional needs, and it concluded that randomized studies were successful in modifying insensitive parenting $(d=.33)$ and modestly effective in improving security of attachment $(d=$ .20) (Bakermans-Kranenburg, van IJzendoorn, \& Juffer, 2003). Factors in obtaining the most successful results were a moderate number of sessions and a specific behavioral focus, even when dealing with multi-problem families. Effective results occurred even when interventions began later than birth. Improving parental sensitivity enhanced attachment security, supporting a hypothesized causal link between sensitivity and attachment. Most studies concerned mothers only, but three reports included fathers, also, with positive results. (See the Appendix for more information on attachment research).

\section{Neonatal Behavioral Assessment Scale and the Touchpoints Approach ${ }^{\mathrm{TM}}$}

Dr. T. Berry Brazelton developed two widely used programs, one for infants and one for young children. The NBAS is used to examine individual differences in newborns' behavior and to facilitate parents' awareness of infants' competencies, helping parents to be sensitive to their infants' cues (Brazelton \& Nugent, 1995; Nugent, 2010). Sensitivity to infants' cues promotes stronger infant-parent attachment. Further, the NBAS is relevant to cognitive development because the infant is at the sensorimotor stage, the first of four stages of cognitive development, according to Piaget's cognitive development theory (Tuckman \& Monetti, 2010). His theory concerned how humans acquire, construct, and use knowledge. In the first stage, infants come to understand the world by the connections they make between experiences with physical, motor actions (Santrock, 2008). Stable dimensions of the NBAS found across many studies include range of state (infant arousal), motor performance, regulation of state under differing levels of stimulation, and autonomic stability (degree of stress related to equilibrium of physiological adjustments within the body) (Costa, Figueiredo, Tendais, Conde, Pacheco, \& Teixeira, 2010; Jacobson, Fein, Jacobson, \& Schwartz, 1984; Lester, Als, \& Brazelton, 1982; Osofsky \& O’Connell, 1977).

The well-known NBAS teaching technique is appropriate for infants up to the age of 2 months. The primary concept is that full-term healthy newborns are social beings structured to give feedback to the caregiver that enhances appropriate caregiving behavior. Although usually performed one on one in an interactive manner, it can be administered in group settings, also (Gaziano \& O'Leary, 1998; Pearson, 1996). (See the Appendix for further information).

The appropriately trained professional obtains responses at whatever state the infants are in and demonstrates to parents or caregivers how they can model their responses to elicit desired behaviors in their babies. The professional guides caregivers through a process of learning about babies' behaviors. A complete NBAS can take an hour or more, including scoring, but a shorter modified one can also be performed. The full scale includes 28 behavioral and 18 reflex items and can be used in a variety of research settings and studies.

The NBAS provides a means of demonstrating good parenting skills without focusing on the parents' behavior and arousing their anxieties about their behavior. It provides an opportunity to allow parents to feel proud and to show off their babies to others, validating their importance as significant people in their babies' lives.

Eiden and Reifman (1996) assessed 13 published investigations of parenting interventions based on the NBAS, finding an overall effect size of $d=.345$, considered small to medium. The NBAS can be effective with high-risk samples (Britt \& Myers, 1994).

Brazelton and his colleagues also developed a Touchpoints Approach ${ }^{\mathrm{TM}}$, emphasizing key points in young children's development to help professionals work with caregivers to identify and anticipate spurts and regressions in the behavior of young children (Brazelton, 1994; Brazelton \& Sparrow, 2003). It aims to help parents deal with self-doubts and frustrations and improve parenting skills.

\section{THE NEED FOR INTERVENTIONS TO IMPROVE PARENTING KNOWLEDGE AND SENSITIVITY}

The vast array of results speaks compellingly to the need to develop and improve more intervention programs that address cognitive and vocabulary development in very early childhood. Hart and Risley (2003, p. 9) explained:

"Cognitively, experience is sequential: Experiences in infancy establish habits of seeking, noticing, and incorporating new and more complex experiences, as well as schemas for categorizing and thinking about experiences. Neurologically, infancy is a critical period because cortical development is influenced by the amount of central nervous system activity stimulated by experience. Behaviorally, infancy is a unique time of helplessness when nearly all of children's experience is mediated by adults in one-to-one interactions permeated with affect. Once children become independent and can speak for themselves, they gain access to more opportunities for experience. But the amount and diversity of children's past experience influences which new opportunities for experience they notice and stipekse" Ryan (1997) suggested that if cognitive development in early childhood is improved, motivation will follow. They reported: “...failure to improve cognitive competencies of children before they enter school [emphasis added] appears to set many disadvantaged children on a trajectory of low academic achievement and all of the negative social and personal outcomes that are associated with poor school performance" (p. 722).

An Optimal Time to Intervene Is with New Parents. The prenatal and early postnatal periods, with their simultaneous excitement and uncertainty, are times when parents are both vulnerable and open to support and new information (Brazelton, 1994; Kowalenko, Barnett, Fowler, \& Matthey, 2000). These are critical times for helping parents develop 
Antecedents of Knowledge Gaps

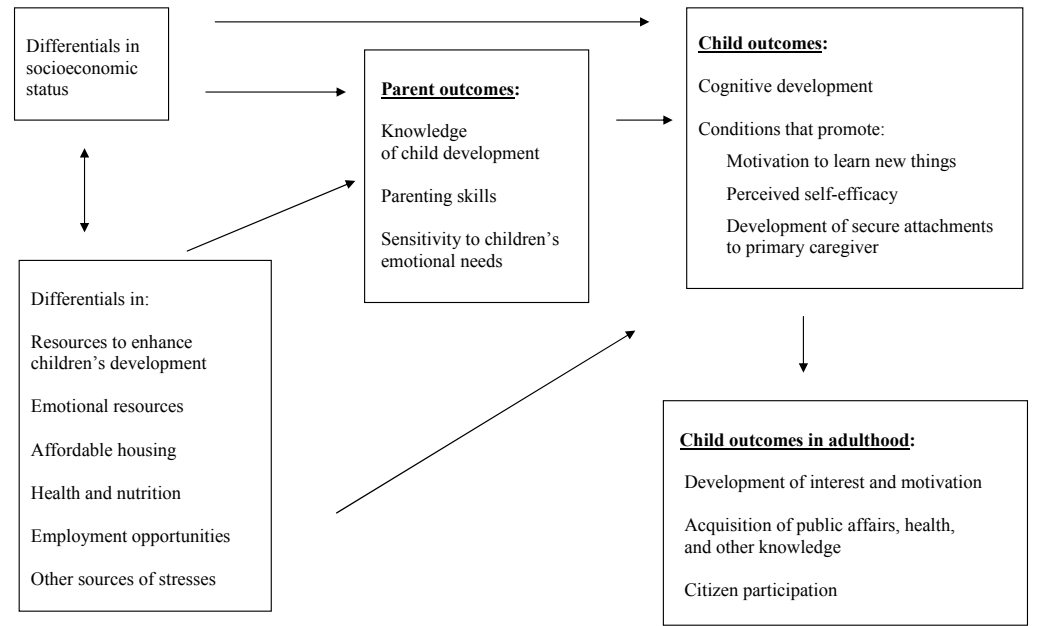

Fig. (2). Conceptual model of the relations among SES and related variables, parent outcomes, and child outcomes.

key skills and knowledge, including sensitive, responsive care-giving and knowledge about their infants' capabilities and normative behavioral development. The transition to parenthood and the infancy period are stressful times for parents, especially so for at-risk parents (Brazelton, 1994; Brazelton \& Sparrow, 2003; Izzo, Eckenrode, Smith, Henderson, Cole, Kitzman, \& Olds, 2005; Kowalenko, Barnett, Fowler, \& Matthey, 2000). Different models of parental support show that parent education, home visiting as a strategy to deliver information to parents, and other strategies can decrease parental stress.

Reviews of major work in this area demonstrate that short-term preventive interventions in at-risk populations are effective in improving parenting knowledge and increasing parental sensitivity about young children's emotional needs, leading to benefits in children's cognitive and motivational development. Even when effect sizes are modest, their implications for improved parent-child relationships are important. Communication researchers may wish to consider developing large-scale, multi-site, longitudinal research programs to reduce knowledge and participation disparities and to study the relationship of such areas as family communication patterns, political socialization, media effects, media use, and others to knowledge gaps. They could collaborate with researchers who specialize in such fields as child development, social work, sociology, health care, and child psychology. Research could begin before babies are born and follow children from birth through adolescence or adulthood. The result may be a fuller picture of what it takes in children's early development to produce informed, engaged citizens. Other communication theories may be enhanced, as well, for instance, integration of family communication theories in knowledge gap research.

\section{SUMMARY}

Knowledge gaps are addressed in two ways in the present paper: interventions can contribute to the reduction of parents' child development knowledge differentials, and they can contribute to improved cognitive development of children, potentially diminishing knowledge gaps in adulthood between more and less advantaged social segments.
The primary theses of this paper are the following, as diagrammed in Fig. (2): Differentials in parents' knowledge about parenting and child development are often founded in SES differentials. Parents' knowledge gaps about child development tend to lead to restricted development of children's cognitive abilities, interest in learning new things, and perceptions of self-efficacy. Understanding of these processes can provide ways of diminishing knowledge gaps. Improvements in parenting knowledge and skills are crucial to supporting schools' efforts to decrease learning differentials.

The processes that foster knowledge and motivation differentials begin very early in life and are often related to many SES factors, especially because stresses on families and resources for dealing with them tend to be unequally distributed in society. In order to know more about reducing knowledge gaps, communication researchers could join forces with child development and other professionals to focus on new parents, infants, and early childhood far more than they do at present. Communication researchers may not think about children in the context of the knowledge gap, but they could use their talents to work toward reducing parenting knowledge and skills gaps and enhancing children's cognitive development.

\section{APPENDIX}

\section{More Information About Training and Measurement}

The IT-HOME. Materials are available for low cost at the following website: http://ualr.edu/case/index.php/home/home-inventory/contact-information/. Retrieved September $1,2011$.

AAPI-2 Materials. For a description of the AAPI-2 materials, cost, and how to obtain them see: http://www.nurturingparenting.com/aapi/aapi2_info.php (retrieved September 1, 2011). Applicants fill out a brief questionnaire in order to be approved. Family Development Resources, Inc. (FDR) in Asheville, NC, responds within 48 hours, regarding approval and online log-in procedures for purchase of instruments and processing. Costs range from $\$ 10.00$ per assessment for a minimum purchase of 10 assessments to $\$ 2.50$ per assess- 
ment for between 60 and 400 assessments to $\$ 2.00$ an assessment for more than 1,000 assessments.

The KIDI. The KIDI and accompanying materials can be ordered at nominal cost from the Educational Testing Service Test Collection Library (see MacPhee, 1981).

Infant Attachment. Many universities offer programs in child psychology, early childhood development, and infant attachment. One leader in the field is the Irving B. Harris Training Center, University of Minnesota. An example of an intervention found successful in promoting secure parentchild attachment and healthy social-emotional development among children in high-risk families is the Steps Toward Effective, Enjoyable Parenting ${ }^{\mathrm{TM}}$ program $\left(\mathrm{STEEP}^{\mathrm{TM}}\right)$ (Erickson \& Egeland, 2004; Erickson, Egeland, Simon, \& Rose, 2002; Erickson, Korfmacher, \& Egeland, 1992; Sroufe, 2005). Seeing Is Believing ${ }^{\mathrm{TM}}$ is a core strategy within the STEEP ${ }^{\mathrm{TM}}$ program (Erickson, 2000; DVD, 2005). Parent-infant interaction is videotaped, as parents are engaged in guided self-observation to build parental understanding and sensitivity to infant cues. Trained professionals talk with parents about their infant while videotaping them, gathering information and encouraging parental insight and emotional connections with their infants. They then view the tapes with the parents, leading the parents to discover how their baby is communicating with them and how best to respond to their baby's needs and strengths. Among the principles of the program is recognition of how stress and support affect the parent-child relationship. Another example of a videotaping strategy is in van Zeijl, Mesman, van IJzendoorn, Bakermans-Kranenburg, Juffer, Stolk, Koot, \& Alink (2006). An example of a training program and scoring for "the Strange Situation," the foundation of measurement of infant attachment, abstracted from Ainsworth, Blehar, Waters, \& Wall (1978) is available from Waters (2002). Although whether attachment should be measured as a categorical or a continuous variable has been debated (e.g., Fraley \& Spieker, 2003), categorical classifications are considered to be valid and reliable. Volume 39, issue 3, of Developmental Psychology contains six articles on measurement issues.

The NBAS and Touchpoints Training. Training in either the NBAS or Touchpoints Approach ${ }^{\mathrm{TM}}$ is offered by the Brazelton Institute in Boston, affiliated with the Harvard Medical School. It requires a substantial cost and time commitment for self study, practice, and certification phases. For example, becoming certified in either Part I or Part II of the NBAS is $\$ 1,000$. Related materials are not expensive. A Touchpoints individual level training program is a 3-day seminar for health care, early education, child care, and social service providers who want to integrate Touchpoints into their practice settings. Priced at $\$ 1,200$ and limited to 25 participants at a seminar, the training is offered several times a year in Boston and sometimes in other locations. Detailed information about these programs is available from the Brazelton Institute, 1295 Boylston Street, Suite 320, Boston, MA 02215 USA; phone 857-218-4354, or at http://www.brazelton-institute.com/ (retrieved September 1, 2011).

\section{NOTES}

1. There are two approaches to conceptualization of family communication patterns. Earlier formulations (mentioned above) focused on more parent-centered views of decision making and control, but later approaches have given more emphasis to children's influences on parents as well (e. g., Graham, 2009; Koerner \& Fitzpatrick, 2002).

2. "For unto every one that hath shall be given, and he shall have abundance: but from him that hath not shall be taken away even that which he hath."

3. Many of the studies discussed included a home-visiting intervention, although interventions in other settings were involved, also, such as homeless shelters, school programs, and clinics. Sweet and Appelbaum (2004) compared 60 programs utilizing a home visiting component but varying in goals, target populations, program services, children's ages during implementation, program length, and type of home visitors (professional, paraprofessional, or non-professional). By far the majority of program goals included parent education and child development. Only reports of whole group comparisons and end of treatment services were included. Standardized effect sizes were computed for all relevant outcomes. Generally, children of families in intervention groups did better than those in control groups. Effect sizes for children and parents were small. The authors argued, however, that even small effects of a reduction in child abuse, for example, were of substantive significance.

4. Cohen's $d=M_{1}-M_{2} / \delta_{\text {pooled }}$ where $\delta_{\text {pooled }}=\sqrt{ }\left[\left(\delta_{1}^{2}+\delta_{2}^{2}\right) /\right.$ 2].

\section{ACKNOWLEDGEMENT}

None declared.

\section{CONFLICT OF INTEREST}

None declared.

\section{REFERENCES}

Ainsworth, M.D.S., Blehar, M.C., Waters, E., \& Wall, S. (1978). Patterns of attachment: A psychological study of the Strange Situation. Hillsdale, NJ: Erlbaum.

Bakermans-Kranenburg, M.J., van IJzendoorn, M.H., \& Bradley, R. H. (2005). Those who have, receive: The Matthew effect in early childhood intervention in the home environment. Review of Educational Research, 75, 1-26.

Bakermans-Kranenburg, M.J., van IJzendoorn, M.H., \& Juffer, F. (2003). Less is more: Meta-analyses of sensitivity and attachment interventions in early childhood. Psychological Bulletin, 129, 195-215.

Barlow, J., Davis, H., McIntosh, E., Jarrett, P., Mockford, C., \& StewartBrown, S. (2007). Role of home visiting in improving parenting and health in families at risk of abuse and neglect: Results of a multicentre randomised controlled trial and economic evaluation. Archives of Disease in Childhood, 92, 229-233.

Barnet, B., Duggan, A.K., DeVoe, M., \& Burrell, L. (2002). The effect of volunteer home visitation for adolescent mothers on parenting and mental health outcomes: A randomized trial. Archives of Pediatrics \& Adolescent Medicine, 156, 1216-1222.

Barnet, B., Liu, J., DeVoe, M., Alperovitz-Bichell, K., \& Duggan, A. K. (2007). Home visiting for adolescent mothers: Effects on parenting, maternal life course, and primary care linkage. Annals of Family Medicine, 5, 224-232. 
Baumrind, D. (1966). Effects of authoritative parental control on child behavior. Child Development, 37, 887-907.

Baumrind, D. (1968). Authoritarian vs. authoritative parental control. Adolescence, 3, 255-272.

Baumrind, D. (1971). Current patterns of parental authority. Developmental Psychology Monograph, 4, (1, Pt. 2), 1- 103.

Baumrind, D. (1994). The social context of child maltreatment. Family Relations, 43, 360-368.

Baumrind, D. (1996). The discipline controversy revisited. Family Relations, 45, 405-414.

Bavolek, S.J. (2001a). Adult Adolescent Parenting Inventory. In: Corcoran, K., \& Fischer, J. (Eds.), Measures for Clinical Practice: A sourcebook (Vol. 1, pp. 204-206) ( $3^{\text {rd }}$ ed.). New York: Free Press.

Bavolek, S.J. (2001b). The Florida report: The impact of gender, race, income and education on parenting attitudes: July 1999 to July 2001. Asheville, NC: Family Development Resources, Inc.

Belcher, H.M.E., Watkins, K., Johnson, E., \& Ialongo, N. (2007). Early Head Start: Factors associated with caregiver knowledge of child development, parenting behavior, and parenting stress. NHSA Dia$\log , 10,6-19$.

Benasich, A.A., \& Brooks-Gunn, J. (1996). Maternal attitudes and knowledge of child-rearing: Associations with family and child outcomes. Child Development, 67, 1186-1205.

Berger, L.M., \& Brooks-Gunn, J. (2005). Socioeconomic status, parenting knowledge and behaviors, and perceived maltreatment of young low-birth-weight children. Social Service Review, 72, 237-267.

Bowlby, J. (1988). A secure base: Clinical applications of attachment theory. London: Routledge.

Bradley, R.H., \& Caldwell, B.M. (1988). Using the HOME Inventory to assess the family environment. Pediatric Nursing, 14, 97-102.

Bradley, R.H., Corwyn, R.F., McAdoo, H.P., \& García Coll, C. (2001), The home environments of children in the United States Part I: Variations by age, ethnicity, and poverty status. Child Development, 72, 1844-1867

Brazelton, T.B. (1994). Touchpoints: Opportunities for preventing problems in the parent-child relationship. Acta Paediatrica Supplement, 394, 35-39.

Brazelton T.B., \& Nugent, J.K. (1995). Neonatal Behavioral Assessment Scale. $\left(3^{\text {rd }}\right.$ ed.). New York: Cambridge University Press.

Brazelton, T.B., \& Sparrow, J.D. (2003). The Touchpoints ${ }^{\mathrm{TM}}$ Model of Development. Boston, MA: Brazelton Touchpoints Center, Children's Hospital.

Britt, G.C., \& Myers, B.J. (1994). The effects of Brazelton intervention: A review. Infant Mental Health Journal, 15, 278-292.

Brooks-Gunn, J., Klebanov, P. K., \& Duncan, G. J. (1996). Ethnic differences in children's intelligence test scores: Role of economic deprivation, home environment, and maternal characteristics. Child Development, 67, 396-408.

Brown, B., \& Rosenbaum, L. (1984). Stress and Competence. In: Humphrey, J. H. Ed., Stress in Childhood: Selected Essays (pp. 127154). New York: AMS Press.

Caldwell, B.M., \& Bradley, R.H. (2001). Home Observation for Measurement of the Environment (HOME) Inventory Administration Manual ( $3^{\text {rd }}$ ed.). Little Rock: University of Arkansas.

Cohen, J. (1988). Statistical Power Analysis for the Behavioral Sciences $\left(2^{\text {nd }}\right.$ ed.). Hillsdale, NJ: Erlbaum.

Conners, N.A., Whiteside-Mansell, L., Deere, D., Ledet, T., \& Edwards, M. C. (2006). Measuring the potential for child maltreatment: The reliability and validity of the Adult Adolescent Parenting Inventory-2. Child Abuse \& Neglect, 30, 39-53.

Costa, R., Figueiredo, B., Tendais, I., Conde, A., Pacheco, A., \& Teixeira, C. (2010). Brazelton Neonatal Behavioral Assessment Scale: A psychometric study in a Portuguese sample. Infant Behavior \& Development, 33, 510-517.

Cowen, P.S. (2001). Effectiveness of a parent education intervention for at risk families. Journal of the Society of Pediatric Nurses, 6, 73-82.

Crittenden, P.M. (1985). Social networks, quality of childrearing, and child development. Child Development, 56, 1299-1313.

Crittenden, P.M. (1996). Research on maltreating families: Implications for intervention. In: Briere, J., Berliner, L., Bulkley, A., Jenny, C., \& Reid, T. (Eds.), The APSAC handbook on child maltreatment (pp. 158-174). Thousand Oaks, CA: Sage.

Culp, A.M., Culp, R.E., Blankemeyer, M., \& Passmark, L. (1998). Parent education home visitation program: Adolescent and nonadolescent mother comparison after 6 months of intervention. Infant Mental Health Journal, 19, 111-123.
Delli Carpini, M.X., \& Keeter, S. (1996). What Americans Know about Politics and Why it Matters. New Haven: Yale University Press.

de Ruiter, C., \& van IJzendoorn, M. H. (1993). Attachment and cognition: A review of the literature. International Journal of Educational Research, 19, 525-540.

Duncan, G., \& Brooks-Gunn, J. (Eds.). (1997). Consequences of growing up poor. New York: Russell Sage Foundation.

East, P.L., Matthews, K.L., \& Felice, M.E. (1994). Qualities of adolescent mothers' parenting. Journal of Adolescent Health, 15, 163-168.

Egeland, B., \& Erickson, M.F. (1999). Findings from the parent child project and implications for early intervention. Zero to Three, 20(2), 310

Eiden, R.D., \& Reifman, A. (1996). Effects of Brazelton demonstrations on later parenting: A meta-analysis. Journal of Pediatric Psychology, $21,857-868$

Erickson, M.F. (2000; DVD, 2005). Seeing Is Believing TM training videos (DVD). Minneapolis, MN: Irving B. Harris Programs, University of Minnesota.

Erickson, M.F., \& Egeland, B. (2004). Linking theory and research to practice: The Minnesota longitudinal study of parents and children and the STEEP TM program. Clinical Psychologist, 8, 5-9.

Erickson, M.F., Egeland, B., Simon, J., \& Rose, T. (2002). STEEP ${ }^{\mathrm{TM}}$ facilitator's guide. Minneapolis, MN: Irving B. Harris Training Center, University of Minnesota.

Erickson, M.F., Korfmacher, J., \& Egeland, B.R. (1992). Attachments past and present: Implications for therapeutic intervention with motherinfant dyads. Developmental Psychology, 4, 495-507.

Erickson, M.F., Sroufe, L.A., \& Egeland, B. (1985). The relationship between quality of attachment and behavior problems in preschool in a high-risk sample. In: Bretherton, I., \& Waters, E. (Eds.), Monographs of the Society for Research in Child Development, 50, 147 166.

Farah, M.J., Betancourt, L., Shera, D.M., Savage, J.H., Giannetta, J. M., Brodsky, N. L., Malmud, E. K., \& Hurt, H. (2008). Environmental stimulation, parental nurturance and cognitive development in humans. Developmental Science, 11, 793-801.

Fraley, R.C., \& Spieker, S.J. (2003). Are infant attachment patterns continuously or categorically distributed? A taxometric analysis of Strange Situation behavior. Developmental Psychology, 39, 387-404.

Gaziano, C. (1997). Forecast 2000: Widening knowledge gaps. Journalism \& Mass Communication Quarterly, 74, 237-264.

Gaziano, C. (2001). Toward a broader conceptual framework for research on social stratification, childrearing patterns, and media effects. Mass Communication \& Society, 4, 219-244.

Gaziano, C., \& Erickson, M.F. (2000). How concepts from attachment theory may help to explain knowledge gaps: A preliminary report. Paper accompanying a poster presented to the American Association for Public Opinion Research, Portland, OR.

Gaziano, C., \& Gaziano, E. (2009). Theories and methods in knowledge gap research. In: Stacks, D.W., \& Salwen, M. (Eds.), An Integrated Approach to Communication Theory and Research (2nd ed., pp. 122136). New York: Taylor \& Francis.

Gaziano, C., \& O'Leary, J. (1998). Childbirth and infant development knowledge gaps in interpersonal settings. Journal of Health Communication, 3, 29-51.

Gorzka, P.A. (1999). Homeless parents: Parenting education to prevent abusive behaviors. Journal of Child \& Adolescent Psychiatric Nursing, 12, 101-109.

Graham, E.E. (2009). Revised Family Communication Patterns instrument (RFCP). In: Rubin, R.B., Rubin, A.M., Graham, E.E., Perse, E.M., \& Seibold D.R. (Eds.), Communication Research Measures II: A sourcebook (pp. 314-323). New York: Routledge.

Greenspan, S.I., \& Wieder, S. (2006). Infant and early childhood mental health: A comprehensive developmental approach to assessment and intervention. Arlington, VA: American Psychiatric Publishing, Inc.

Grossman, K.E., Grossman, K., \& Waters, E. (2005). Attachment from Infancy to Adulthood: The Major Longitudinal Studies. New York: Guilford Press.

Guthrie, K.F., Gaziano, C., \& Gaziano, E.P. (2009). Toward Better Beginnings: Enhancing healthy child development and parent-child relationships in a high-risk population. Home Health Care Management \& Practice, 21, 99-108.

Hackman, D.A., \& Farah, M. J. (2009). Socioeconomic status and the developing brain. Trends in Cognitive Sciences, 13, 65-73. 
Hackman, D.A., Farah, M.J., \& Meaney, M.J. (2010). Socioeconomic status and the brain: mechanistic insights from human and animal research. Nature Reviews Neuroscience, 11, 651-659.

Hamilton, M.A., \& Orme, J.G. (1990). Examining the construct validity of three parenting knowledge measures using LISREL. Social Service Review, 64, 121-143.

Hart, B., \& Risley, T.R. (1995). Meaningful Differences in the Everyday Experience of Young American Children. Baltimore, MD: Brookes Publishing Co.

Hart, B., \& Risley, T.R. (2003). The early catastrophe: The 30 million word gap by age 3. American Educator, 27, 4-9.

Hurlbut, N.L., Culp, A.M., Jambunathan, S., \& Butler, P. (1997). Adolescent mothers' self-esteem and role identity and their relationship to parenting skills knowledge. Adolescence, 32(127), 639-654.

Huth-Bocks, A.C., Levendosky, A.A., Bogat, G.A., \& von Eye, A. (2004). The impact of maternal characteristics and contextual variables on infant-mother attachment. Child Development, 75, 480-496.

Hwang, Y., \& Jeong, S.H. (2009). Revisiting the knowledge gap hypothesis: A meta-analysis of thirty-five years of research. Journalism \& Mass Communication Quarterly, 86, 513-532.

Izzo, C.V., Eckenrode, J.J., Smith, E.G., Henderson, C.R., Jr., Cole, R., Kitzman, H., \& Olds, D.L. (2005). Reducing the impact of uncontrollable stressful life events through a program of nurse home visitation for new parents. Prevention Science, 6, 269-274.

Jacobson, J.L., Fein, G.G., Jacobson, S.W., \& Schwartz, P.M. (1984). Factors and clusters for the Brazelton Scale: An investigation of the dimensions of neonatal behavior. Developmental Psychology, 20, 339-353.

Kendrick, D., Elkan, R., Hewitt, M., Dewey, M., Blair, M., Robinson, J., Williams, D., \& Brummell, K. (2000). Does home visiting improve parenting and the quality of the home environment? A systematic review and meta analysis. Archives of Disease in Childhood, 82, 443-451.

Koerner, A.F., \& Fitzpatrick, M.A. (2002). Toward a theory of family communication. Communication Theory, 12, 70-91.

Kohn, M.L. (1976). Social class and parental values: Another confirmation of the relationship. American Sociological Review, 41, 538-545.

Kohn, M.L. (1977). Class and Conformity: A Study in Values, with a Reassessment $\left(2^{\text {nd }}\right.$ ed.). Chicago: University of Chicago Press.

Korfmacher, J. (2000). The Kempe family stress inventory: A review. Child Abuse \& Neglect, 24, 129-140.

Kowalenko, N., Barnett, B., Fowler, C., \& Matthey, S. (2000). The perinatal period: Early interventions for mental health. In: Kosky, R., O'Hanlon, A., Martin, G., \& Davis, C. (Eds.), Clinical Approaches to Early Intervention in Child and Adolescent Mental Health (pp. 2331). Adelaide, Australia: Australian Early Intervention Network for Mental Health in Young People.

Lester, B.M., Als, H., \& Brazelton, T.B. (1982). Regional obstetric anesthesia and newborn behavior: A reanalysis toward synergistic effects. Child Development, 53, 687-692.

Linver, M. R., Brooks-Gunn, J., \& Cabrera, N. (2004). The Home Observation for Measurement of the Environment (HOME) Inventory: The derivation of conceptually designed subscales. Parenting: Science and Practice, 4, 99-114.

Lutenbacher, M., \& Hall, L.A. (1998). The effects of maternal psychosocial factors on parenting attitudes of low-income, single mothers with young children. Nursing Research, 47, 25-34.

Maccoby, E.E., \& Martin, J.A. (1983). Socialization in the context of the family: Parent-child interaction. In: Mussen, P.H. (Ed.), Handbook of Child Psychology (pp. 1-101). New York: Wiley.

MacPhee, D. (1981). Knowledge of Infant Development Inventory (Vol. Call \# TC016431). Princeton, NJ: Educational Testing Service (ETS) Test Collection Library. Available from: www.ets.org/testcoll/pdflist.html

Main, M., \& Solomon, J. (1986). Discovery of a disorganized disoriented attachment pattern. In: Brazelton, T.B., \& Yogman, M.W. (Eds.), Effective Development in Infancy (pp. 95-124). Norwood, NJ: Ablex.

McLeod, D.M., \& Perse, E.M. (1994). Direct and indirect effects of socioeconomic status on public affairs knowledge. Journalism Quarterly, 71, 433-442.

McLeod, J.M., \& O'Keefe, G.J. (1972). The socialization perspective and communication behavior. In: Kline, F.G., \& Tichenor, P.J. (Eds.), Current Perspectives in Mass Communication Research (pp. 121168). Beverly Hills: Sage.
McLoyd, V.C. (1990). The impact of economic hardship on black families and children: Psychological distress, parenting, and socioemotional development. Child Development, 61, 311-346.

Merton, R.K. (1968). The Matthew effect in science. Science, 159(3810), 56-63.

Munz, E.A., Wilson, S.R., \& D'Enbeau, S. (2010). The reach of child abuse potential: Its relationship with features of parenting at home. Journal of Family Communication, 10, 256-277.

Neuman, S.B. (2006a). How we neglect knowledge-and why. American Educator, 30, 24-27.

Neuman, S.B. (2006b). The knowledge gap: Implications for early education. In: Dickinson, D., \& Neuman, S.B. (Eds.), Handbook of Early Literacy Research (pp. 29-40). New York: Guilford.

Nugent, J.K. (2010). The development of the NBAS: A turning point in understanding the newborn. In: Lester, B.M., \& Sparrow, J.D (Eds.), Nurturing Children and Families: Building on the Legacy of T. Berry Brazelton (pp. 42-52). Malden, MA: Blackwell Publishing, Ltd.

Olds, D.L., Eckenrode, J.J., Henderson, C.R., Jr., Kitzman, H., Powers, J., Cole, R., Sidora, K., Morris, P., Pettitt, L. M., \& Luckey, D. (1997). Long-term effects of home visitation on maternal life course and child abuse and neglect. Fifteen-year follow-up of a randomized trial. Journal of the American Medical Association, 278, 637-643.

Oliver, M.B., \& Armstrong, G.B. (1995). Predictors of viewing and enjoyment of reality-based and fictional crime shows. Journalism \& Mass Communication Quarterly, 72, 559-570.

Osofsky, J.D., \& O'Connell, E.J. (1977). Patterning of newborn behavior in an urban population. Child Development, 48, 532-536.

Pearson, J. (1996). Using the NBAS in a group setting: A model for parent educators. Ab Initio: The Brazelton Institute Newsletter, 3, 4-5.

Peterson, B.E., Duncan, L.E., \& Pang, J.S. (2002). Authoritarianism and political impoverishment: Deficits in knowledge and civic disinterest. Political Psychology, 23, 97-112.

Petrill, S.A., \& Deater-Deckard, K. (2004). Task orientation, parental warmth and SES account for a significant proportion of the shared environmental variance in general cognitive ability in early childhood: Evidence from a twin study. Developmental Science, 7, 2532 .

Petrill, S.A., Pike, A., Price, T., \& Plomin, R. (2004). Chaos in the home and socioeconomic status are associated with cognitive development in early childhood: Environmental mediators identified in a genetic design. Intelligence, 32, 445-460.

Pfost, K.S., Stevens, M.J., \& Lum, C.U. (1990). The relationship of demographic variables, antepartum depression, and stress to postpartum depression. Journal of Clinical Psychology, 46, 588-592.

Reynolds, A.J., \& Robertson, D.L. (2003). School-based early intervention and later child maltreatment in the Chicago Longitudinal Study. Child Development, 74, 3-26.

Ritchie, L.D. (1991). Family communication patterns: An epistemic analysis and conceptual reinterpretation. Communication Research, 18, 548-565.

Rowe, M.L. (2008). Child-directed speech: Relation to socioeconomic status, knowledge of child development and child vocabulary skill. Journal of Child Language, 35, 185-205.

Rueger, S.Y., Katz, R.L., Risser, H.J., \& Lovejoy, M.C. (2011). Relations between parental affect and parenting behaviors: A meta-analytic review. Parenting: Science and Practice, 11, 1-33.

Santrock, J.W. (2008). A Topical Approach to Life-Span Development. New York, NY: McGraw-Hill.

Sasso, T.K., \& Williams, S.K. (2002). The effectiveness of The Parenting Curriculum: An evaluation of high school students' questionnaire responses. Journal of Family and Consumer Sciences Education, 20, 1-11.

Simmons, R.E., \& Garda, E.C. (1982). Dogmatism and the "knowledge gap" among Brazilian mass media users. Gazette, 30, 121-133.

Sroufe, L.A. (1983). Infant-caregiver attachment and patterns of adaptation in preschool: The roots of maladaption and competence. In: Perlmutter, M. (Ed.), Development and Policy Concerning Children with Special Needs: The Minnesota Symposia on Child Psychology (pp. 41-79). Hillsdale, NJ: Erlbaum.

Sroufe, L.A. (2005). Attachment and development: A prospective, longitudinal study from birth to adulthood. Attachment \& Human Development, 7, 349-367. 
St. Pierre, R.G., \& Layzer, J.I. (1999). Using home visits for multiple purposes: The Comprehensive Child Development Program. The Future of Children, 9, 134-151.

Stipek, D.J., \& Ryan, R.H. (1997). Economically disadvantaged preschoolers: Ready to learn but further to go. Developmental Psychology, 33, 711-723.

Sweet, M.A., \& Appelbaum, M.I. (2004). Is home visiting an effective strategy? A meta-analytic review of home visiting programs for families with young children. Child Development, 75, 1435-1456.

Thomas, D.V., \& Looney, S.W. (2004). Effectiveness of a comprehensive psychoeducational intervention with pregnant and parenting adolescents: A pilot study. Journal of Child and Adolescent Psychiatric Nursing, 17, 66-77.

Tichenor, P.J., Donohue, G.A., \& Olien, C.N. (1970). Mass media flow and differential growth in knowledge. Public Opinion Quarterly, 34, $159-170$.

Tims, A.R., \& Masland, J.L. (1985). Measurement of family communication patterns. Communication Research, 12, 35-57.

Totsika, V., \& Sylva, K. (2004). The Home Observation for Measurement of the Environment revisited. Child and Adolescent Mental Health, 9, 25-35.

Tuckman, B.W., \& Monetti, D.M. (2010). Educational Psychology. Belmont, CA: Wadsworth.

Turkheimer, E., Haley, A., Waldron, M., D’Onofrio, B., \& Gottesman, I.I. (2003). Socioeconomic status modifies heritability of IQ in young children. Psychological Science, 14, 623-628.

van Zeijl, J., Mesman, J., van IJzendoorn, M. H., Bakermans-Kranenburg, M.J., Juffer, F., Stolk, M.N., Koot, H.M., \& Alink, L.R.A. (2006).
Attachment-based intervention for enhancing sensitive discipline in mothers of 1- to 3-year-old children at risk for externalizing behavior problems: A randomized controlled trial. Journal of Consulting and Clinical Psychology, 74, 994-1005.

Viswanath, K., \& Finnegan, J.R., Jr. (1996). The knowledge gap hypothesis: Twenty-five years later. In: Burleson, B.R. (Ed.), Communication Yearbook 19 (pp. 187-227). Thousand Oaks, CA: Sage.

Wagner, M., Spiker, D., \& Linn, M.I. (2002). The effectiveness of the parents as teachers program with low-income parents and children. Topics in Early Childhood Special Education, 22, 67-81.

Waters, E. (2002). Comments on Strange Situation classification. Retrieved on: $1^{\text {st }}$ September 2011, from http://www.psychology.sunysb.edu/attachment/measures/content/ss_scoring.pdf.

Woods, E.R., Obeidallah-Davis, D., Sherry, M.K., Ettinger, S.L., Simms, E.U., Dixon, R.R., Missal, S.M., \& Cox, J.E. (2003). The parenting project for teen mothers: The impact of a nurturing curriculum on adolescent parenting skills and life hassles. Ambulatory Pediatrics, 3, 240-245.

Zeanah, C.H., Benoit, D., Hirshberg, L., Barton, M.L., \& Regan, C. (1994). Mothers' representations of their infants are concordant with infant attachment classifications. Developmental Issues in Psychiatry and Psychology, 1, 9-18.

Zolotor, A.J., Burchinal, M., Skinner, D., \& Rosenthal, M., \& Key Life Investigators. (2008). Maternal psychological adjustment and knowledge of infant development as predictors of home safety practices in rural low-income communities. Pediatrics, 121, e 1668e1675.

Received: October 11, 2011

Revised: December 11, 2011

Accepted: December 13, 2011

(C) Cecilie Gaziano; Licensee Bentham Open.

This is an open access article licensed under the terms of the Creative Commons Attribution Non-Commercial License (http://creativecommons.org/licenses/by-nc/3.0/) which permits unrestricted, non-commercial use, distribution and reproduction in any medium, provided the work is properly cited. 